\title{
SUPPLEMENT TO: GLOBAL MODELING OF ORGANIC AEROSOL: THE IMPORTANCE OF REACTIVE NITROGEN
}

\author{
H. O. T. PYE ${ }^{1}$, A. W. H. CHAN ${ }^{1}$, M. BARKLEY ${ }^{2}$, AND J. H. SEINFELD ${ }^{1}$ \\ ${ }^{1}$ Division of Chemistry and Chemical Engineering, California Institute of \\ Technology, Pasadena, California, USA \\ ${ }^{2}$ School of GeoSciences, University of Edinburgh, Edinburgh, Scotland, UK
}

The supplemental information (Fig. S1-S3) shows the chamber data and fits based on those data described in Table 1 (main manuscript). The first column shows the data plotted as yield (mass of aerosol formed divided by mass of parent hydrocarbon reacted) vs. organic aerosol loading (mass of aerosol formed in $\mu \mathrm{g} / \mathrm{m}^{3}$ ). Fits are shown at the reference temperature $(298 \mathrm{~K})$ and data are shown at the experimental temperature (usually around $298 \mathrm{~K}$, but about $310 \mathrm{~K}$ for sesquiterpenes and $\beta$-pinene $+\mathrm{NO}_{3}$ ). The right column shows the modeled yield based on the fit (corrected for temperature using an enthalpy of vaporization of $42 \mathrm{~kJ} / \mathrm{mol}$ ) vs. the measured yield from the chamber experiment. The dotted line is the 1:1 line.

Date: August 16, 2010. 

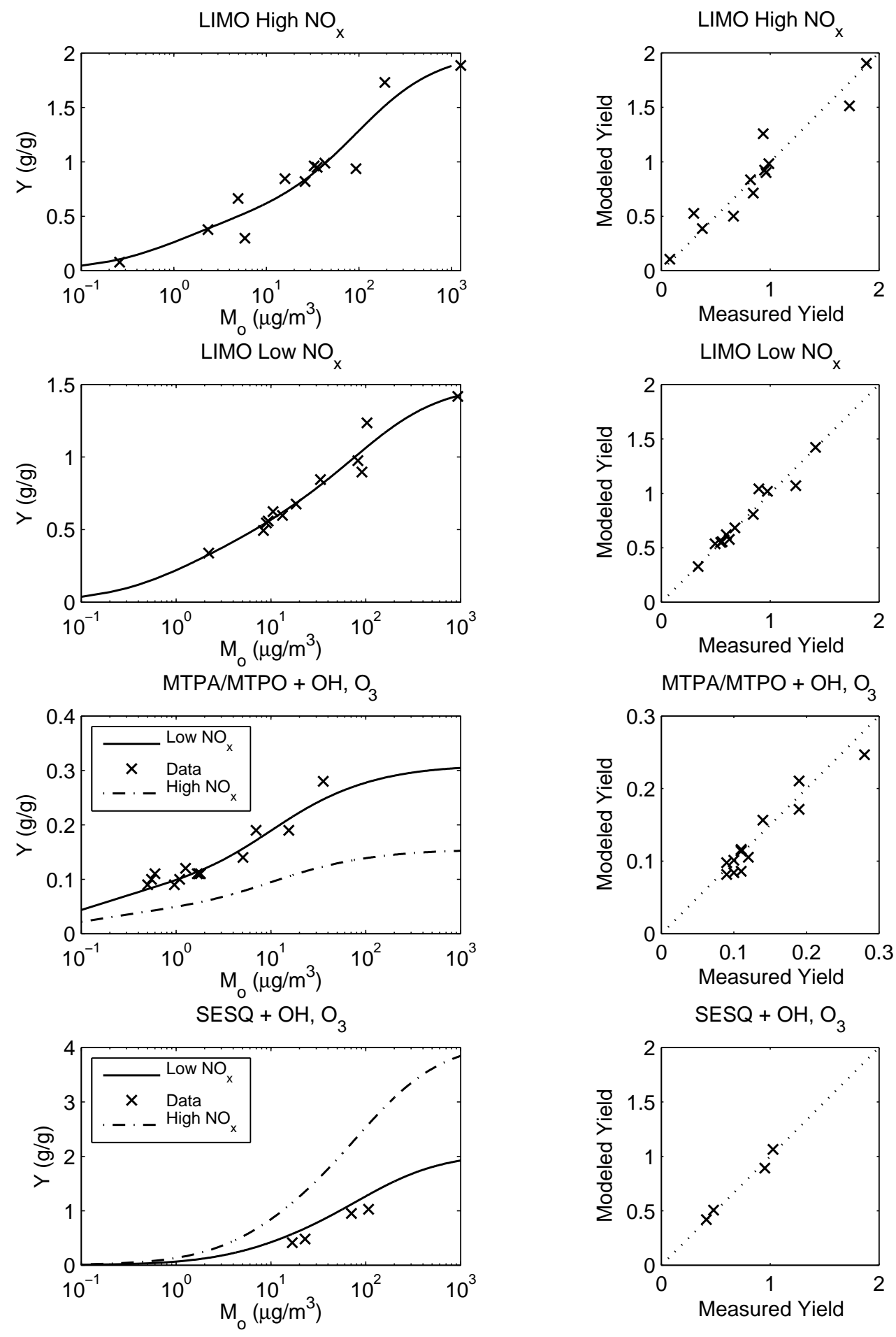

FiguRE S1. Aerosol yields from high- and low- $\mathrm{NO}_{x}$ terpene oxidation. 

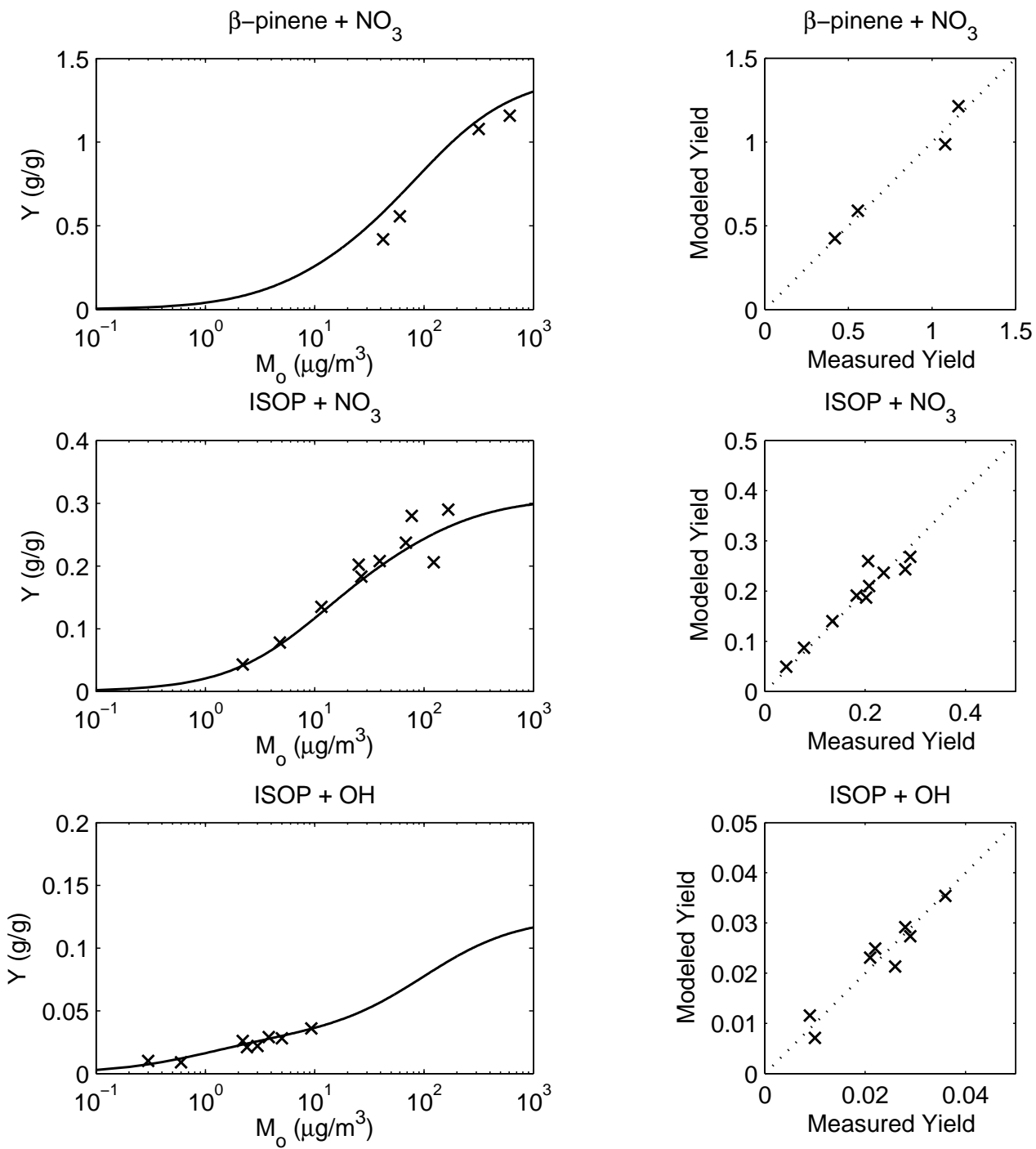

FiguRE S2. Aerosol yields from nitrate radical oxidation (of terpenes and isoprene) and isoprene photooxidation. 

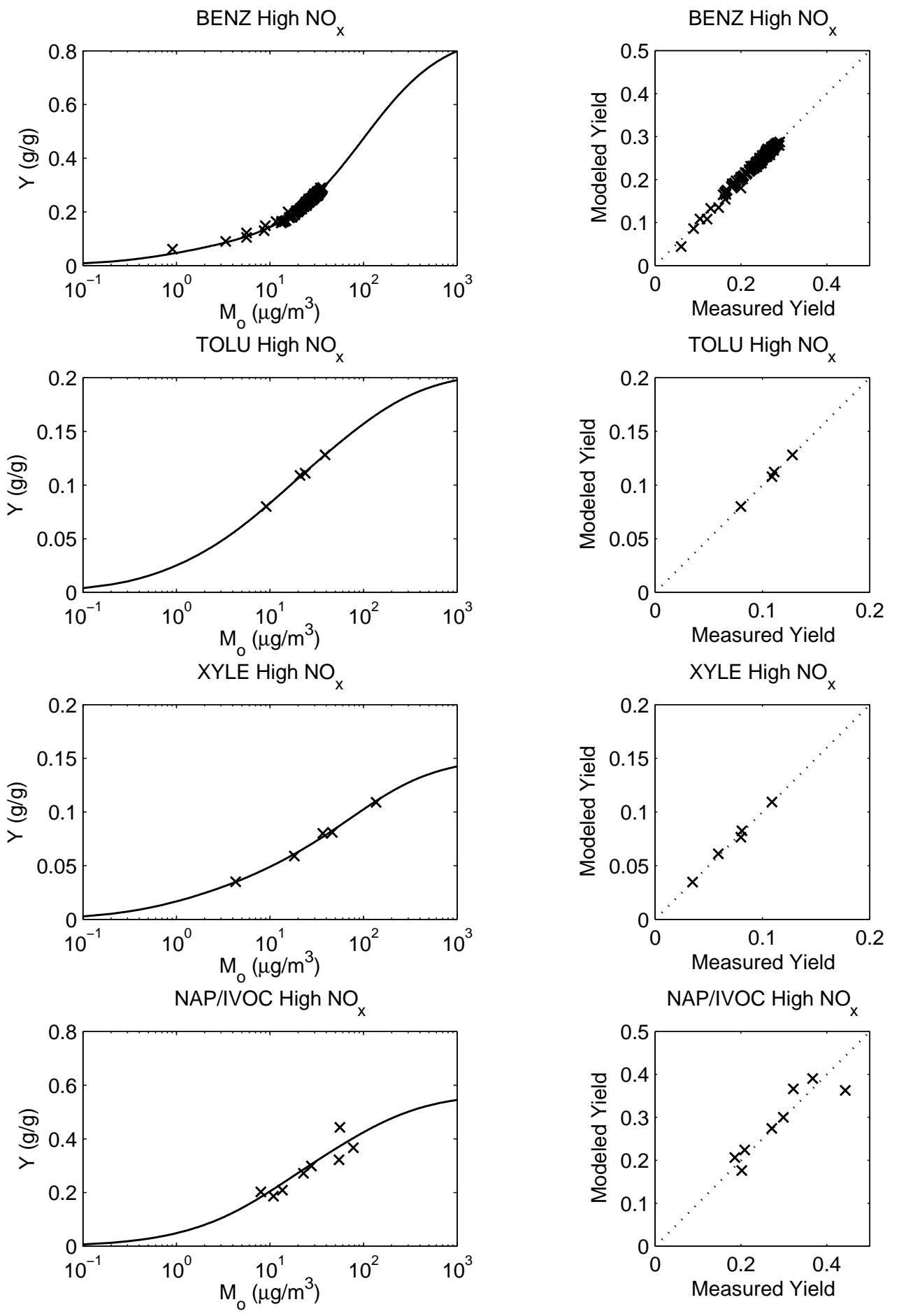

Figure S3. Aerosol yields from light aromatic and naphthalene high- $\mathrm{NO}_{x}$ photooxidation. 